\title{
The relationship between maternal psychiatric disorder, autism spectrum disorder and intellectual disability in the child: a composite picture
}

\author{
Jenny Fairthorne ${ }^{1 *}$, Nick de Klerk² and Helen Leonard'
}

*Correspondence: Jenny.Fairthorne@telethonkids.org.au

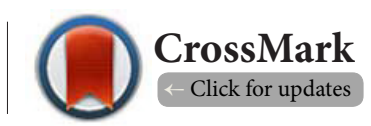

'Department of Developmental Disability, Telethon Kids Institute, University of Western Australia, Perth, Australia. ${ }^{2}$ Department of Biostatistics, Telethon Kids Institute, University of Western Australia, Perth, Australia.

\begin{abstract}
Objective: Our four previous research papers examined the relationship between maternal psychiatric disorders and having a child with autism spectrum disorder or intellectual disability (ASD or ID). Here, we aimed to discuss and integrate these results.

Methods: We used regression analyses of rates based on data from state-based, linkable registries.

Results: Women with a psychiatric disorder were about twice as likely to have a child with ASD or ID. Of mothers with no psychiatric history, those with a child with ASD or ID were about twice as likely to have a psychiatric disorder after the birth as mothers with no child with ASD or ID. During the study period, mothers with both a psychiatric disorder and a child with ASD or ID were at the highest risk of death, followed in succession by mothers with only a psychiatric disorder, mothers with only a child with ASD or ID, and mothers with neither a psychiatric disorder nor a child with ASD or ID.

Conclusions: The increased odds of a child with ASD or ID in women with a psychiatric disorder could be due to genetics and/or a poorer antenatal environment. The higher rate of new onset disorders in mothers with a child with ASD or ID could have been due to a higher burden of care. Mothers with both a psychiatric disorder and a child with ASD or ID faced the greatest challenges. Extra support is needed for mothers of children with ASD or ID (and particularly those with a psychiatric disorder) to enable them to maintain their mental health and to successfully meet the challenges of raising their child.
\end{abstract}

Keywords: Autism, intellectual disability, maternal, psychiatric, linked data, health

\section{Background}

Since the eighties, research into maternal psychiatric disorders and child disability has focused on psychiatric issues in mothers caring for a child with autism spectrum disorder (ASD) or intellectual disability (ID). Interest in pre-existing disorders has been limited and focused almost exclusively on ASD [1-3]. We only found one research paper which explored pre-existing maternal psychiatric disorder and the risk of ID in subsequent children [4]. Qualitative research [5-8] has established that parenting a child with ASD or ID is more demanding than parenting other children and quantitative observational studies studies [9-12] have indicated that parenting a child with ASD or ID increases the risk of stress or mental health problems. Furthermore, researchers are continuing to investigate possible genetic associations between psychiatric disorders with
ASD and ID [13-16]. To date, one conclusion is that a particular genetic deletion is a risk factor for psychiatric disease and ID [13]. Another is that schizophrenia and bipolar disorder share a common biological pathway with ASD [14]. A third is that a copy number variant at a particular genetic location is a risk factor for both schizophrenia and ASD [15].

Although life expectancy is reduced in those with psychiatric conditions [17], we found no studies exploring the relationship between maternal mortality, mental health status and having a child with ASD or ID. An association between pre-existing psychiatric disorder and the odds of having a child with ASD or ID could implicate antenatal exposures in women with psychiatric disorders or assist in the unravelling of the associated genetics. Comparing the rates of psychiatric disorders in women with and without a child with ASD or ID and no

(c) 2015 Fairthorne et al; licensee Herbert Publications Ltd. This is an Open Access article distributed under the terms of Creative Commons Attribution License (http://creativecommons.org/licenses/by/3.0). This permits unrestricted use, distribution, and reproduction in any medium, provided the original work is properly cited. 
Fairthorne et al. Journal of Autism 2015,

psychiatric history prior to their birth would assist in quantifying the relative burden of care in these groups, which could be different between sub-types of ASD and/or ID. Having a psychiatric disorder increases the risk of death and having a child with ASD or ID increases the risk of a psychiatric disorder but what is the increased risk of death in women with both a psychiatric disorder and a child with ASD or ID? Again, we might find a particular group of women at higher risk of earlier death than others.

With these factors in mind, we conducted research using population-based linked data from registries in Western Australia (WA). These included the Intellectual Disability Exploring Answers (IDEA) Database which includes reliable ASD diagnoses of ASD made by a multidisciplinary team using DSM-4. Diagnoses of ID were based on age-appropriate developmental or psychometric testing by clinicians or psychologists. In keeping with DSM-4, scores of two standard deviations below the mean were required for IQ and adaptive functioning, along with an onset before 18 years. Other databases we accessed were the Midwives Notification System, the Mental Health Information System, the Hospital Morbidity Data System, and the Birth and Death Registries.

Using logistic and negative binomial regression, we adjusted for the socio-demographic variables, socioeconomic status (SES), maternal age and parity at the birth of the index child using the records of around 250,000 mothers. Four publications resulted [18-21]. The first [18] calculated the odds of a child with ASD or ID in women with pre-existing psychiatric disorders and the second [19] compared the risk of death in women with both a psychiatric disorder and a child with ASD or ID, women with one of these traits and women with neither. In the third and fourth papers [20,21], we calculated that risk of a psychiatric disorder in women with no psychiatric history and a child with ASD [20] or ID [21] compared to other women. In the current paper, we aim to integrate and discuss the results and implications of these previous papers.

\section{Review \\ Results}

We found that women with a psychiatric disorder were about twice as likely to have a child with ASD or ID as women without a psychiatric history [18]. Mothers with no psychiatric history and a child with ASD or ID were about twice as likely to have a new onset psychiatric disorder after the birth of their child than other mothers with no psychiatric history $[\mathbf{2 0 , 2 1 ]}$. In these studies, we showed that mothers at highest odds of a psychiatric disorder were mothers of a child with ASD without ID, with nearly two and a half times the risk [20], followed by mothers of children with ID of unknown cause with more than one and a half times the risk (Figure 1) [21].

Compared to mothers with no psychiatric disorder and no child with ASD or ID, mothers with both a psychiatric disorder and a child with ASD or ID were about six and a half times as likely to die during the study period [19]. Mothers with a psychiatric disorder only had about four times the risk of death and mothers with a child with ASD or ID and no psychiatric

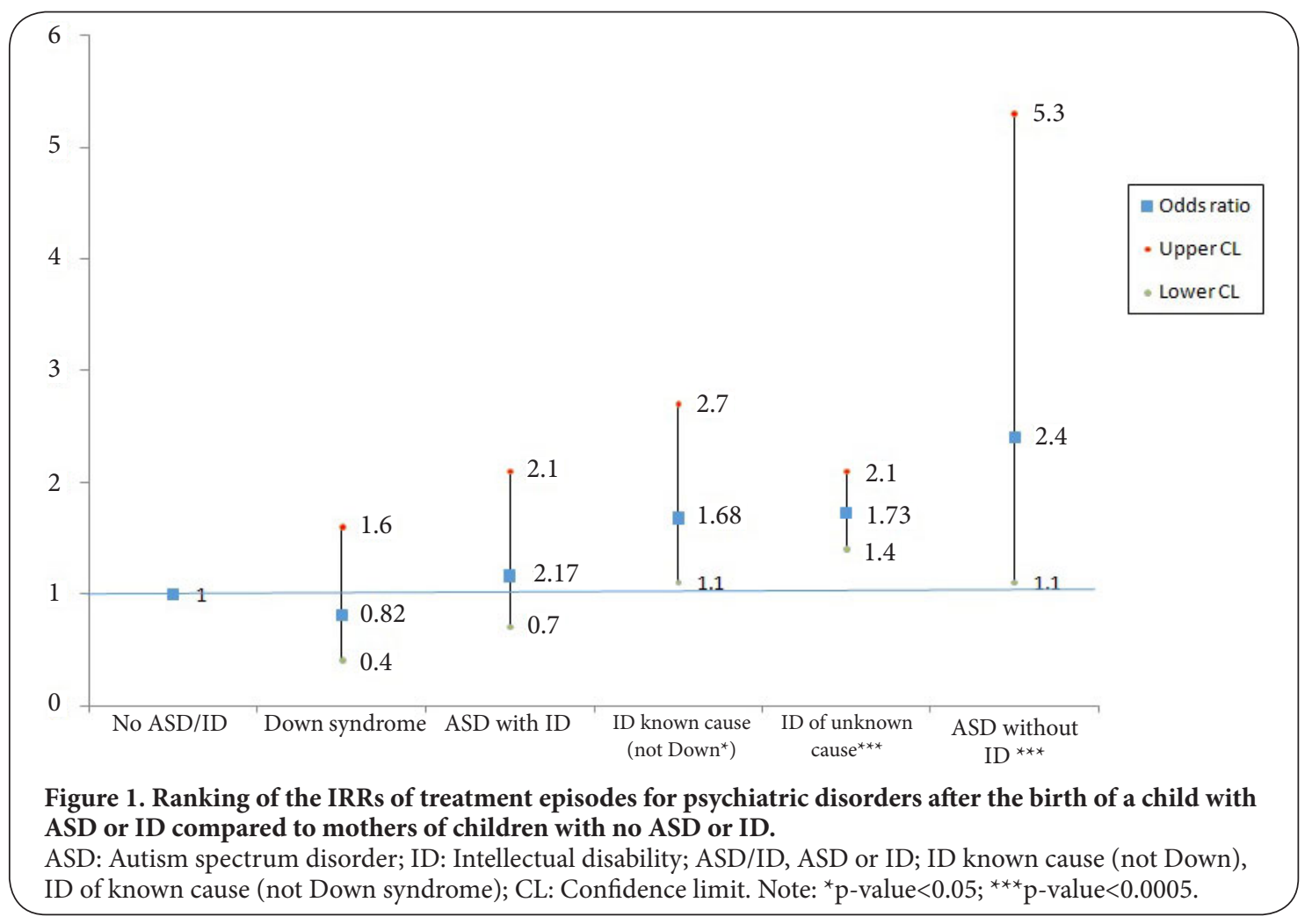


Fairthorne et al. Journal of Autism 2015,

http://www.hoajonline.com/journals/pdf/2054-992X-2-2.pdf

disorder had about a 50\% increased risk of death (Figure 2) [19].

\section{Discussion}

Our studies showed that maternal psychiatric disorders, ASD and ID are related in multiple ways. As we did $[\mathbf{1 8}, \mathbf{2 0}]$, other research groups have demonstrated that mothers of children with ASD are more likely to have a psychiatric disorder $[1,3,22]$ than other mothers. But only one research group had established an association with ID and maternal psychiatric disorders (severe ID only) [4]. We showed that mothers with any psychiatric disorder, mild or severe, were twice as likely to have a child with ID [18]. Furthermore, we showed that the risk of ID in the children of mothers with a psychiatric disorder is just as high as that of ASD $[\mathbf{2 0 , 2 1 ]}$. The higher risk of ASD or ID in women with a previous psychiatric disorder might be due to the common genetic factors of ASD, ID and some psychiatric disorders. Alternatively, women with a psychiatric disorder are more likely to be taking medication during their pregnancies and there is evidence that anti-psychotic [23], anti-depressant $[\mathbf{2 3}, \mathbf{2 4}]$ and anti-epileptic medications [25] affect fetal neurodevelopment. However, certain irregularities of the placenta are more common in women with psychiatric illness. For example, women with schizophrenia are more likely to have a placental abruption than other women [26]. This might contribute to the higher rates of ASD or ID in the offspring due to the resulting oxygen and nutrient deprivation of the fetus.

Secondly, our studies $[\mathbf{2 0}, \mathbf{2 1}]$ of new onset psychiatric disorders in mothers of children with ASD or ID demonstrated about twice the contact rate in these mothers compared to other mothers. As no mother had a psychiatric history, we considered that these higher rates could be attributable to the increased challenges of caring for their child.

The results of our study of early mortality in mothers of children with ASD or ID [19] indicated that both having a psychiatric disorder and caring for a child with ASD or ID each individually impacted significantly on mortality. Moreover, having a psychiatric disorder had greater impact on mortality than having a child with ASD or ID. The effect of each of these circumstances was cumulative since mothers with both a psychiatric disorder and a child with ASD or ID were the most vulnerable to early death.

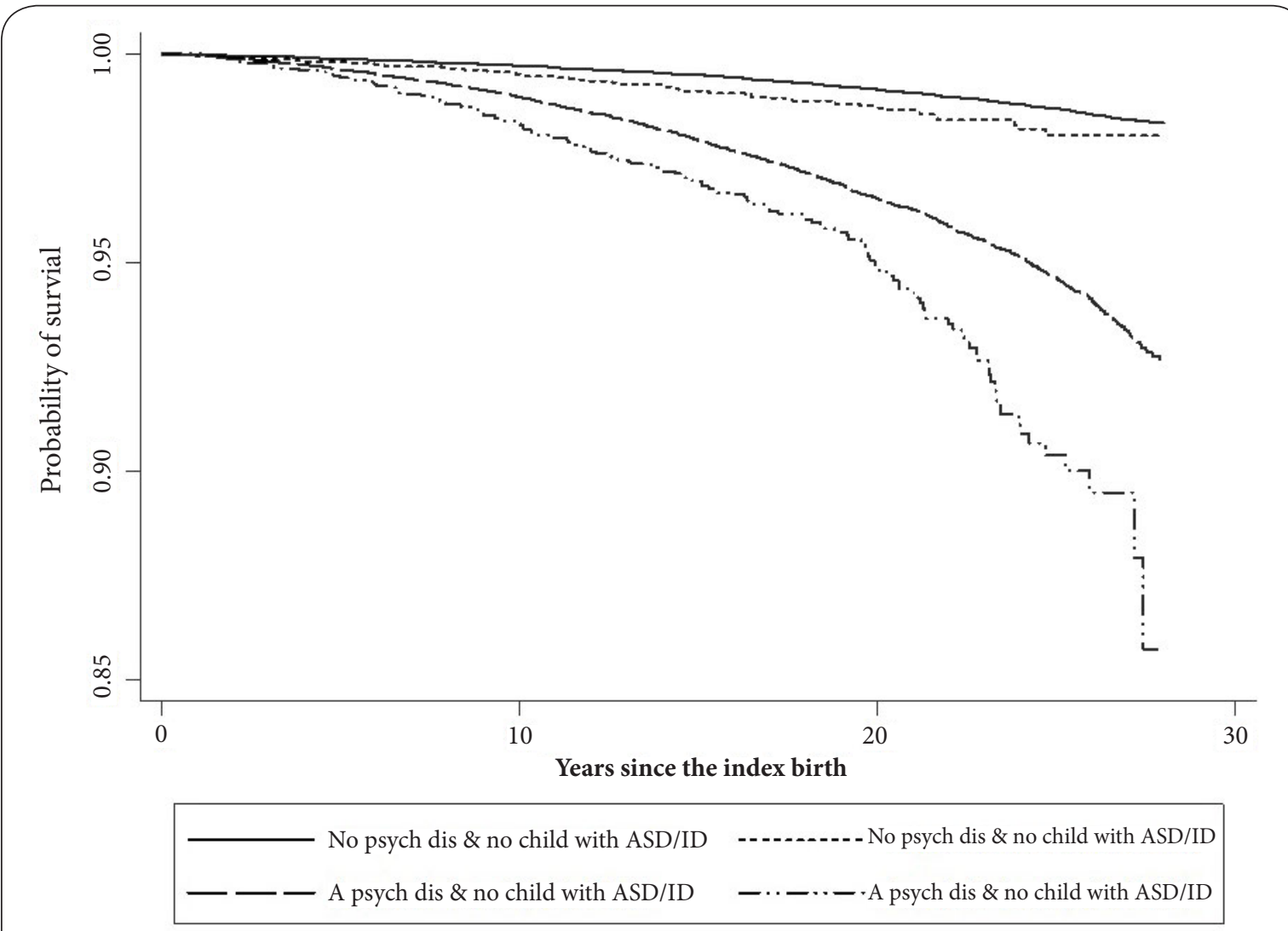

Figure 2. Differential survival of mothers according to having a psychiatric disorder and a child with ASD/ID. Psych dis, psychiatric disorder; ASD, autism spectrum disorder; ID, intellectual disability; ASD/ID, ASD or ID. Note 1: Figure is adapted from Fairthorne et al. 2014. [19].

Note 2: More than 20 years after the index birth, numbers of deaths in mothers with a psych dis and a child with ASD/ID are small. 
Fairthorne et al. Journal of Autism 2015,

http://www.hoajonline.com/journals/pdf/2054-992X-2-2.pdf

doi: 10.7243/2054-992X-2-2

\section{Strengths and limitations}

Selection bias was minimal in these large population-based studies, each of around 200,000-300,000 mothers. In addition, we were able to access statutory diagnostic mental health data collected over more than 30 years that was not reliant on maternal or family recall. This enabled us to reliably identify mothers with a psychiatric disorder. Similarly, our use of the IDEA database [27] with its diagnoses of ASD or ID from clinical and education sources made each study possible.

Our psychiatric diagnoses were collected from inpatient and outpatient sources. Unfortunately, the outpatient data did not include information on private patients. This would have had the effect of attenuating our results, since a small proportion of women who appeared to have no psychiatric history would have had a private outpatient contact. In assessing psychiatric status, we equated a hospital admission with an outpatient appointment which did not take into account the length of stay, or possible overall differences in the severity of psychiatric disorders associated with each type of contact. Three $[\mathbf{1 8 , 2 0 , 2 1 ]}$ of our analyses adjusted for SES using an area level proxy rather than an individual level proxy. Because we used state-based records, a few mothers with all psychiatric records from elsewhere would have been incorrectly categorised as comparator mothers. Lastly, our data did not allow us to distinguish between women with a psychiatric disorder who did and did not take medication during pregnancy which would have enabled us to compare the rates of ASD or ID in their subsequent offspring.

\section{Conclusion}

Our finding that mothers with a psychiatric disorder were more likely to have a child with ASD or ID suggests the need for further research on medication use in pregnancy. After the birth, women with a child with ASD or ID and no psychiatric history were more vulnerable to psychiatric disorders than other mothers. In WA, dependent children or adults with ASD or ID commonly remain resident in their family home as long as the parents or other primary caregivers are able to continue providing care. At this point, which is usually a crisis, the parents may apply to a government agency for the funding for suitable alternative accommodation for their child [28]. Hence, it is vital that these caregivers, particularly those of children with ASD without ID, receive more support to assist them to maintain their health. In WA, it is ironic that this very vulnerable group may not receive government-funded resources if their child is diagnosed after the age of six years since this is the age at which funding for early intervention cuts out. We suggest that resources be available to these women after the diagnosis of their child of any age. This might be in the form of interventions to assist these children to improve their sociability and behaviour and workshops to assist parents in managing their child's difficult or inappropriate behaviours. In such ways, these women may be enabled to improve their mental health and subsequently their family's quality of life.
In terms of mortality, mothers with both a psychiatric disorder and a child with ASD or ID have the highest risk. It is important that these women are given extra support to enable them to meet the challenges of raising their children.

\section{Competing interests}

The authors declare that they have no competing interests.

Authors' contributions

\begin{tabular}{|l|c|c|c|}
\hline Authors' contributions & JF & NK & HL \\
\hline Research concept and design & $\checkmark$ & $\checkmark$ & $\checkmark$ \\
\hline Collection and/or assembly of data & $\checkmark$ & -- & -- \\
\hline Data analysis and interpretation & $\checkmark$ & $\checkmark$ & -- \\
\hline Writing the article & $\checkmark$ & -- & -- \\
\hline Critical revision of the article & $\checkmark$ & $\checkmark$ & $\checkmark$ \\
\hline Final approval of article & $\checkmark$ & $\checkmark$ & $\checkmark$ \\
\hline Statistical analysis & $\checkmark$ & $\checkmark$ & -- \\
\hline
\end{tabular}

\section{Acknowledgement}

The authors are grateful to Disability Services Commission, Telethon Kids Institute, Western Australian Department of Education, Catholic Education Office and the Association of Independent Schools of Western Australia for assistance with data collection for the IDEA database. This research was funded by an Australian Post-graduate Award, a University of Western Australia PhD Completion Scholarship and the Stan and Jean Perron Award (JF only). Professor Leonard was supported by Australian National Health and Medical Research Council (NHMRC) Program Grant \#572742.

Publication history

Editor: Michael B. Blank, University of Pennsylvania, USA. Received: 10-Aug-2015 Final Revised: 18-Sep-2015 Accepted: 19-Oct-2015 Published: 26-Oct-2015

\section{References}

1. Jokiranta E, Brown AS, Heinimaa M, Cheslack-Postava K, Suominen A and Sourander A. Parental psychiatric disorders and autism spectrum disorders. Psychiatry Res. 2013; 207:203-11. | Article I PubMed Abstract | PubMed Full Text

2. Larsson HJ, Eaton WW, Madsen KM, Vestergaard M, Olesen AV, Agerbo E, Schendel D, Thorsen P and Mortensen PB. Risk factors for autism: perinatal factors, parental psychiatric history, and socioeconomic status. Am J Epidemiol. 2005; 161:916-25. I Article I PubMed

3. Daniels JL, Forssen U, Hultman CM, Cnattingius S, Savitz DA, Feychting $\mathrm{M}$ and Sparen P. Parental psychiatric disorders associated with autism spectrum disorders in the offspring. Pediatrics. 2008; 121:e1357-62. | Article I PubMed

4. Morgan VA, Croft ML, Valuri GM, Zubrick SR, Bower C, McNeil TF and Jablensky AV. Intellectual disability and other neuropsychiatric outcomes in high-risk children of mothers with schizophrenia, bipolar disorder and unipolar major depression. Br J Psychiatry. 2012; 200:2829. I Article | PubMed

5. Fairthorne J, Fisher C, Bourke J and Leonard H. Experiences impacting the quality of life of mothers of children with autism and intellectual disability. Psychology Research. 2014; 4:666-84. I Article

6. Woodgate RL, Ateah C and Secco L. Living in a world of our own: the experience of parents who have a child with autism. Qual Health Res. 2008; 18:1075-83. | Article | PubMed

7. Shearn J and Todd S. Maternal employment and family responsibilities: the perspectives of mothers of children with intellectual disabilities. Journal of Applied Research in Intellectual Disabilities. 2000; 13:109-31. | Article 
Fairthorne et al. Journal of Autism 2015,

8. Edwardraj S, Mumtaj K, Prasad JH, Kuruvilla A and Jacob KS. Perceptions about intellectual disability: a qualitative study from Vellore, South India. J Intellect Disabil Res. 2010; 54:736-48. | Article I PubMed

9. Blacher J, Lopez S, Shapiro J and Fusco J. Contributions to depression in Latina mothers with and without children with retardation: implications for caregiving. Family Relations. 1997; 46:325-34. | Article

10. Browne $G$ and Bramston P. Stress and the quality of life in the parents of young people with intellectual disabilities. J Psychiatr Ment Health Nurs. 1998; 5:415-21. | Article | PubMed

11. Baker-Ericzén $M$, Brookman-Frazee $L$ and Stahmer A. Stress levels and adaptability in parents of toddlers with and without autism spectrum disorders. Research and Practice for Persons with Severe Disabilities. 2005; 30:194-204. I Pdf

12. Eisenhower AS, Baker BL and Blacher J. Preschool children with intellectual disability: syndrome specificity, behaviour problems, and maternal well-being. J Intellect Disabil Res. 2005; 49:657-71. | Article | PubMed Abstract | PubMed Full Text

13. Vinas-Jornet M, Esteba-Castillo S, Gabau E, Ribas-Vidal N, Baena N, San J, Ruiz A, Coll MD, Novell R and Guitart M. A common cognitive, psychiatric, and dysmorphic phenotype in carriers of NRXN1 deletion. Mol Genet Genomic Med. 2014; 2:512-21. | Article I PubMed Abstract | PubMed Full Text

14. Carroll LS and Owen MJ. Genetic overlap between autism, schizophrenia and bipolar disorder. Genome Med. 2009; 1:102. I Article I PubMed Abstract | PubMed Full Text

15. Maillard AM, Ruef A, Pizzagalli F, Migliavacca E, Hippolyte L, Adaszewski S, Dukart J, Ferrari C, Conus P, Mannik K, Zazhytska M, Siffredi V, Maeder P, Kutalik Z, Kherif F, Hadjikhani N, Beckmann JS, Reymond A, Draganski $B$ and Jacquemont $S$. The $16 p 11.2$ locus modulates brain structures common to autism, schizophrenia and obesity. Mol Psychiatry. 2015; 20:140-7. | Article | PubMed Abstract | PubMed Full Text

16. Chisholm K, Lin A, Abu-Akel A and Wood SJ. The association between autism and schizophrenia spectrum disorders: $A$ review of eight alternate models of co-occurrence. Neurosci Biobehav Rev. 2015; 55:173-83. | Article | PubMed

17. Lawrence D, Jablensky AV, Holman CD and Pinder TJ. Mortality in Western Australian psychiatric patients. Soc Psychiatry Psychiatr Epidemiol. 2000; 35:341-7. | Article I PubMed

18. Fairthorne J, Hammond G, Bourke J, de Klerk N and Leonard H. Maternal Psychiatric Disorder and the Risk of Autism Spectrum Disorder or Intellectual Disability in Subsequent Offspring. J Autism Dev Disord. 2015. I Article | PubMed

19. Fairthorne J, Hammond G, Bourke J, Jacoby P and Leonard H. Early mortality and primary causes of death in mothers of children with intellectual disability or autism spectrum disorder: a retrospective cohort study. PLoS One. 2014; 9:e113430. | Article I PubMed Abstract | PubMed Full Text

20. Fairthorne J, Jacoby P, Bourke J, de Klerk N and Leonard H. Onset of maternal psychiatric disorders after the birth of a child with autism spectrum disorder: A retrospective cohort study. Autism. 2015. | Article I PubMed

21. Fairthorne J, Jacoby $\mathrm{P}$, Bourke J, de Klerk $\mathrm{N}$ and Leonard $\mathrm{H}$. Onset of maternal psychiatric disorders after the birth of a child with intellectual disability: a retrospective cohort study. J Psychiatr Res. 2015; 61:223-30. | Article | PubMed

22. Sullivan PF, Magnusson C, Reichenberg A, Boman M, Dalman C, Davidson M, Fruchter E, Hultman CM, Lundberg M, Langstrom N, Weiser M, Svensson AC and Lichtenstein P. Family history of schizophrenia and bipolar disorder as risk factors for autism. Arch Gen Psychiatry. 2012; 69:1099-1103. | Article | PubMed Abstract | PubMed Full Text

23. Eriksson MA, Westerlund J, Anderlid BM, Gillberg C and Fernell E. Firstdegree relatives of young children with autism spectrum disorders: some gender aspects. Res Dev Disabil. 2012; 33:1642-8. | Article | PubMed

24. Croen LA, Grether JK, Yoshida CK, Odouli R and Hendrick V. Antidepressant use during pregnancy and childhood autism spectrum disorders. Arch Gen Psychiatry. 2011; 68:1104-12. | Article I PubMed
25. Maimburg RD and Vaeth M. Perinatal risk factors and infantile autism. Acta Psychiatr Scand. 2006; 114:257-64. I Article I PubMed

26. Jablensky AV, Morgan V, Zubrick SR, Bower C and Yellachich LA. Pregnancy, delivery, and neonatal complications in a population cohort of women with schizophrenia and major affective disorders. Am J Psychiatry. 2005; 162:79-91. | Article | PubMed

27. Petterson B, Leonard H, Bourke J, Sanders R, Chalmers R, Jacoby P and Bower C. IDEA (Intellectual Disability Exploring Answers): a populationbased database for intellectual disability in Western Australia. Ann Hum Biol. 2005; 32:237-43. | Article I PubMed

28. Disability Services Commission. Accommodation support funding parameters policy. Perth: Government of Western Australia. 2001.

\section{Citation:}

Fairthorne J, Klerk $\mathrm{Nd}$ and Leonard $\mathrm{H}$. The relationship between maternal psychiatric disorder, autism spectrum disorder and intellectual disability in the child: a composite picture. J Autism. 2015; 2:2. http://dx.doi.org/10.7243/2054-992X-2-2 